\title{
Circ_0015756 promotes the progression of ovarian cancer by regulating miR-942-5p/ CUL4B pathway
}

Zhenhua Du* ${ }^{*}$, Lei Wang and Yu Xia

\begin{abstract}
Background: Ovarian cancer (OC) is the gynecologic cancer with the highest mortality. Circular RNAs (circRNAs) play a vital role in the development and progression of cancer. This study aimed to explore the potential role of circ_0015756 in OC and its molecular mechanism.

Methods: The levels of circ_0015756, microRNA-942-5p (miR-942-5p) and Cullin 4B (CUL4B) were determined by quantitative real-time PCR (qRT-PCR) or Western blot assay. Cell proliferation, apoptosis, migration and invasion were assessed by Cell Counting Kit-8 (CCK-8), colony formation assay, flow cytometry and transwell assay. The levels of proliferation-related and metastasis-related proteins were measured by Western blot assay. The relationship between miR-942-5p and circ_0015756 or CUL4B was verified by dual-luciferase reporter assay, RNA immunoprecipitation assay and RNA pull-down assay. Xenograft assay was used to analyze tumor growth in vivo.

Results: Circ_0015756 and CUL4B levels were increased, while miR-942-5p level was decreased in OC tissues and cells. Depletion of circ_0015756 suppressed proliferation, migration and invasion and promoted apoptosis in OC cells. Down-regulation of circ_0015756 hindered OC cell progression via modulating miR-942-5p. Also, up-regulation of miR-942-5p impeded OC cell development by targeting CUL4B. Mechanistically, circ_0015756 up-regulated CUL4B via sponging miR-942-5p. Moreover, circ_0015756 silencing inhibited tumor growth in vivo.
\end{abstract}

Conclusion: Knockdown of circ_0015756 suppressed OC progression via regulating miR-942-5p/CUL4B axis, suggesting that circ_0015756 might be a potential therapeutic target for ovarian cancer.

Keywords: Ovarian cancer, Circ_0015756, miR-942-5p, CUL4B

\section{Highlights}

1. Circ_0015756 was up-regulated in OC tissues and cells.

2. Knockdown of circ_0015756 inhibited OC progression.

3. Circ_0015756 promoted OC progression via miR942-5p/CUL4B axis.

*Correspondence: dr_duzhenhua@163.com

Department of Obstetrics and Gynecology, Shengjing Hospital of China Medical University, NO. 36 Sanhao Street, Heping District, Shenyang

City 110021, Liaoning Province, China
4. Circ_0015756 depletion inhibited OC growth in vivo.

\section{Introduction}

Ovarian cancer $(\mathrm{OC})$ is a malignant tumor of the female reproductive system, and the mortality of epithelial OC ranks first among gynecological cancers [1]. The treatment of OC mainly includes surgery and platinum-based chemotherapy [2]. With the gradual aging of the population, the incidence of $\mathrm{OC}$ is increasing year by year [3]. Due to the lack of specific early clinical symptoms, OC is mostly diagnosed at advanced stage [4]. Therefore, exploring the molecular mechanism of $\mathrm{OC}$ progression

(c) The Author(s) 2020. This article is licensed under a Creative Commons Attribution 4.0 International License, which permits use, sharing, adaptation, distribution and reproduction in any medium or format, as long as you give appropriate credit to the original author(s) and the source, provide a link to the Creative Commons licence, and indicate if changes were made. The images or other third party material in this article are included in the article's Creative Commons licence, unless indicated otherwise in a credit line to the material. If material is not included in the article's Creative Commons licence and your intended use is not permitted by statutory regulation or exceeds the permitted use, you will need to obtain permission directly from the copyright holder. To view a copy of this licence, visit http://creativecommons.org/licenses/by/4.0/. The Creative Commons Public Domain Dedication waiver (http://creativecommons.org/publicdomain/zero/1.0/) applies to the data made available in this article, unless otherwise stated in a credit line to the data. 
to discover effective tumor markers is crucial for diagnosis and treatment of $\mathrm{OC}$.

Circular RNAs (circRNAs) are a new type of endogenous RNAs with a covalent closed-loop structure without $5^{\prime}-3^{\prime}$ polarity [5]. Mounting evidence has corroborated that circRNAs with complex tissue specificity participate in tumorigenesis and development through multiple pathways [6]. Furthermore, circRNAs can serve as promising therapeutic targets for gynecological cancers [7]. For example, circRHOBTB3 impeded OC development by inhibiting PI3K/AKT signaling pathway [8]. Additionally, hsa_circ_0009910 facilitated the malignant behaviors of OC via down-regulating microRNA-145 [9]. Also, hsa_circRNA_102958 aggravated the progression of OC by regulating microRNA-1205/SH2D3A pathway [10]. A previous research revealed that hsa_circ_0015756 derived from complement factor $\mathrm{H}(\mathrm{CFH})$ was significantly up-regulated in OC tissues [11]. Nonetheless, the biological function and potential basis of circ_0015756 in OC have not been investigated.

Compelling evidence has suggested that microRNAs (miRNAs) suppress gene expression by base-pairing with the 3'UTR of target mRNA [12]. Substantial studies have confirmed that miRNAs participate in many cellular processes, including cell differentiation, proliferation and metastasis [13]. For instance, miR-362-3p suppressed the metastasis of cervical cancer by inhibiting BCAP31 [14]. Moreover, miR-486-5p accelerated cell growth and mobility in endometrial carcinoma via repressing MARK1 [15]. Besides, Xie et al. [16] suggested that miR-942 level was conspicuously reduced in OC tissues. Nevertheless, the association between circ_0015756 and miR-942-5p remains unclear.

In this research, we verified that circ_0015756 was remarkably increased in OC. Furthermore, we clarified the function and potential mechanism of circ_0015756 in OC. These findings unveiled that circ_0015756 played a pro-oncogenic role in OC by regulating miR-942-5p/ Cullin 4B (CUL4B) axis, which might provide a new biomarker for OC treatment.

\section{Materials and methods}

\section{Specimen collection}

OC tissues $(\mathrm{n}=55)$ and adjacent normal tissues $(\mathrm{n}=55)$ were obtained from 55 OC patients who underwent oophorectomy at Shengjing Hospital of China Medical University. Two histopathologists independently confirmed the results of all tissue samples. Inclusion criteria were: complete medical records; no treatment started before admission. Exclusion criteria were: recurrent OC; history of other malignancies; other clinical diseases. None of OC patients received any treatment before surgery. All participants signed written informed consent.
The research was ratified by the Ethics Committee of Shengjing Hospital of China Medical University.

\section{Cell culture}

Human normal ovarian epithelial cell line (IOSE80) was purchased from Shanghai and Shanghai Zhen Biotechnology Co., Ltd. (Shanghai, China). Two OC cell lines (OV90 and SKOV3) were commercially acquired from American Type Culture Collection (ATCC, Manassas, VA, USA). All cells were cultured in RPMI-1640 medium (cat no. SH30809.01; Hyclone, Logan, UT, USA) containing $10 \%$ fetal bovine serum (FBS, cat no. SH30084.03; Hyclone) with $5 \% \mathrm{CO}_{2}$ at $37^{\circ} \mathrm{C}$.

\section{Cell transfection}

Circ_0015756 small interfering RNA (si-circ_0015756) and negative control (si-NC), miR-942-5p mimics (miR942-5p) and the control (miR-NC), miR-942-5p inhibitor (anti-miR-942-5p) and the control (anti-miR-NC), CUL4B overexpression vector (pcDNA-CUL4B) and negative control (pcDNA) were synthesized from GenePharma (Shanghai, China). Cell transfection was carried out using Lipofectamine 3000 (cat no. L3000-015; Invitrogen, Carlsbad, CA, USA) when cell confluence reached $\sim 80 \%$.

\section{Quantitative real-time PCR (qRT-PCR)}

RNA was extracted from tissues and cells using Trizol (cat no. R0016; Beyotime, Shanghai, China). Next, the complementary DNA (cDNA) was synthesized using the specific reverse transcription kit (Takara, Dalian, China). Subsequently, the expression level was monitored using SYBR Premix Ex Taq (cat no. RR420A; Takara) and calculated using the $2^{-\Delta \Delta C t}$ method. Glyceraldehyde 3-phosphate dehydrogenase (GAPDH) or U6 were identified as a loading control. The PCR amplification procedure included $95^{\circ} \mathrm{C}$ for $10 \mathrm{~min}$, followed by 40 cycles of $95^{\circ} \mathrm{C}$ for $5 \mathrm{~s}, 60{ }^{\circ} \mathrm{C}$ for $10 \mathrm{~s}$, and $72{ }^{\circ} \mathrm{C}$ for $10 \mathrm{~s}$. The primers included: circ_0015756-F: 5'-TGGACGGAACCACCT CAATG-3', circ_0015756-R: 5'-CCTGAAACCACCCTC ACAAGT-3'; miR-942-5p-F: 5'-AGGGTCTTCTCTGTT

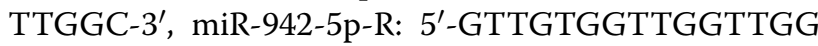
TTTGT-3'; CUL4B-F: 5'-ACTCCTCCTTTACAACCC AGG-3', CUL4B-R: 5'-TCTTCGCATCAAACCCTA CAAAC-3'; GAPDH-F: 5'-GGGAAACTGTGGCGTGAT -3', GAPDH-R: 5'-GAGTGGGTGTCGCTGTTGA-3'; U6-F: 5'-CTCGCTTCGGCAGCACA-3', U6-R: 5'-AAC GCTTCACGAATTTGCGT-3'.

\section{Cell viability assay}

OV90 and SKOV3 cells were plated into 96-well plates at a density of $2 \times 10^{3}$ cells/well after transfection with different combinations. After incubating at $37{ }^{\circ} \mathrm{C}$ for $0 \mathrm{~h}$, 
$24 \mathrm{~h}, 48 \mathrm{~h}$ or $72 \mathrm{~h}, 10 \mu \mathrm{L}$ of Cell Counting Kit-8 (CCK-8, cat no. C0038; Beyotime) solution was added to each well for $2 \mathrm{~h}$. Then, the absorbance was measured at $450 \mathrm{~nm}$ using a Microplate Reader (cat no. CN-13055-50; BioTek, Burlington, VT, USA).

\section{Colony formation assay}

The transfected OV90 and SKOV3 cells were injected into six-well plates and incubated for 2 weeks. After washing with phosphate-buffered saline (PBS, cat no. P1020; Solarbio, Beijing, China), the cells were fixed with $4 \%$ paraformaldehyde and stained with $0.5 \%$ crystal violet (cat no. C8470-25; Solarbio). Finally, the colonies were photographed and counted under a microscope.

\section{Western blot assay}

Total protein was extracted with RIPA buffer (cat no. R0020; Solarbio). Subsequently, the protein samples were quantified using BCA Protein Assay Kit (cat no. ab102536; Abcam, Cambridge, UK) and then separated by $10 \%$ polyacrylamide gel electrophoresis (PAGE) and transferred onto PVDF membranes (cat no. P2938; Sigma, St Louis, MO, USA). After blocking with 5\% nonfat milk for $2 \mathrm{~h}$ at room temperature, the membranes were incubated with primary antibodies against Ki67 (1:5000, cat no. ab92742; Abcam), CDK2 (1:2000, cat no. ab32147; Abcam), Snail (1:500, cat no. ab82846; Abcam), MMP9 (1:1000, cat no. ab38898; Abcam), CUL4B (1:2000, cat no. ab227724; Abcam) or $\beta$-actin (1:2000, cat no. ab8227; Abcam) overnight at $4{ }^{\circ} \mathrm{C}$. After washing three times with TBST for 10 min each time, the membranes were probed with the corresponding HRP-labeled secondary antibody (1:20,000, cat no. ab205718; Abcam) for $2 \mathrm{~h}$ at room temperature. After the secondary antibody incubation, the membranes were rinsed three times with TBST for 10 min each time. Afterwards, the protein bands were examined using the ECL system (cat no. P0018AM; Beyotime).

\section{Flow cytometry}

Cell apoptosis was evaluated using Annexin V-FITC Apoptosis Detection Kit (cat no. C1062M; Beyotime). The transfected OV90 and SKOV3 cells were washed with PBS (cat no. P1020; Solarbio) and then resuspended in binding buffer. Subsequently, the cells were stained with Annexin V-FITC and Propidium Iodide (PI) for $15 \mathrm{~min}$. Finally, the apoptosis rate was assessed by FACScan Flow Cytometry (cat no. BD FACSCalibur 342975; BD Biosciences, San Diego, CA, USA).

\section{Transwell assay}

The transfected OV90 and SKOV3 cells were injected into the upper chamber (cat no. 3422; Corning,
Corning, NY, USA). At the same time, 10\% FBS (cat no. SH30084.03; Hyclone) was injected into the lower chamber as attractant. After culturing for $24 \mathrm{~h}$, the cells were fixed with methanol and stained with $0.1 \%$ crystal violet (cat no. C8470-25; Solarbio). Then, the migrated cells were counted under a microscope at $100 \times$ magnification. The difference in cell invasion test was that transwell was pre-coated with Matrigel (cat no. 354234; Corning).

\section{Dual-luciferase reporter assay}

The wild-type luciferase reporter (circ_0015756WT or CUL4B $3^{\prime}$ UTR-WT) was formed via cloning circ_0015756 or CUL4B 3'UTR containing miR-942-5p binding site into pmirGLO vector (cat no. LM-1439; LMAI Bio, Shanghai, China). The mutant luciferase reporter (circ_0015756-MUT or CUL4B 3'UTR-MUT) was formed via mutating the binding site. Afterwards, the corresponding reporter and miR-NC or miR-942-5p were co-transfected into OV90 and SKOV3 cells. The Firefly and Renilla luciferase activities were measured via Dual-Lucy Assay Kit (cat no. D0010; Solarbio). Firefly luciferase activity was standardized by Renilla luciferase activity.

\section{RNA immunoprecipitation (RIP) assay}

RIP analysis was performed via EZ-Magna RIP kit (cat no. 17-701; Millipore, Billerica, MA, USA) according to the manufacturer's instructions. After lysing OV90 and SKOV3 cells in RIP lysis buffer, cell lysates were treated with magnetic beads combined with Ago2 antibody (antiAgo2) overnight at $4{ }^{\circ} \mathrm{C}$. IgG antibody (anti-IgG) was regarded as a negative control. The precipitated RNAs were purified and measured using qRT-PCR analysis.

\section{RNA pull-down assay}

Biotinylated miR-942-5p (Bio-miR-942-5p) and negative control (Bio-miR-NC) were purchased from GenePharma. OV90 and SKOV3 cells were lysed and then incubated with streptavidin-coated magnetic beads (Invitrogen). Subsequently, the abundance of circ_0015756 was measured using qRT-PCR analysis.

\section{Xenograft assay}

Animal experiments were ratified by the Animal Ethics Committee of Shengjing Hospital of China Medical University. Female BALB/c nude mice (5-week-old) were bought from Beijing Vital River Laboratory Animal Technology Co., Ltd. (Beijing, China) and randomly divided into two groups ( $\mathrm{n}=5$ per group). Lentivirus containing circ_0015756 short hairpin RNA (sh-circ_0015756) or negative control (sh-NC) were purchased from GenePharma and transferred into SKOV3 cells. Then, stably transfected SKOV3 cells $\left(5 \times 10^{6}\right)$ were subcutaneously 
injected into the flank of mice. Tumor volume was measured every 7 days. After 35 days, the mice were sacrificed and the xenograft tumors were weighed.

\section{Statistical analysis}

All data were expressed as mean \pm standard deviation in three independent replicates. The differences were evaluated by Student's $t$-test or one-way analysis of variance through GraphPad Prism 7 software (GraphPad Inc., La Jolla, CA, USA). The linear relationship among circ_0015756, miR-942-5p and CUL4B was assessed using Spearman's correlation analysis. When $P$-value $<0.05$, the difference was considered statistically significant.

\section{Results}

\section{Circ_0015756 is up-regulated in OC tissues and cells}

To clarify the role of circ_0015756 in ovarian cancer, we first detected the expression of circ_0015756 in OC tissues. As illustrated in Fig. 1a, circ_0015756 expression in OC tissues was significantly higher than that in normal tissues. Next, we examined the expression of circ_0015756 in OC cell lines and normal ovarian epithelial cell line. As expected, the level of circ_0015756 in OC cell lines (OV90 and SKOV3) was strikingly increased compared with normal ovarian epithelial cell line (IOSE80) (Fig. 1b). These results suggested that circ_0015756 might be an oncogene in ovarian cancer.

\section{Knockdown of circ_0015756 inhibits the proliferation,} migration and invasion of $\mathrm{OC}$ cells and induces apoptosis

To further explore the biological function circ_0015756 in OC, OV90 and SKOV3 cells were transfected with si-NC or si-circ_0015756. As shown in Fig. 2a, the knockdown efficiency of circ_0015756 was significant. CCK-8 and colony formation assays showed that circ_0015756 silencing suppressed the proliferation of OV90 and SKOV3 cells compared with the control group (Fig. 2bd). Consistently, the levels of proliferation-related proteins (Ki67 and CDK2) were markedly reduced in the si-circ_0015756 group compared to the si-NC group (Fig. 2e, f). Flow cytometry suggested that down-regulation of circ_0015756 promoted the apoptosis of OV90 and SKOV3 cells relative to the control group (Fig. 2g). In addition, transwell assay revealed that silence of circ_0015756 inhibited the migration and invasion of OV90 and SKOV3 cells compared with the control group (Fig. 2h, i). Western blot analysis showed that down-regulation of circ_0015756 remarkably decreased the protein levels of Snail and MMP9 compared with the si-NC group (Fig. 2j, k). Overall, these data indicated that silencing of circ_0015756 suppressed OC cell progression.
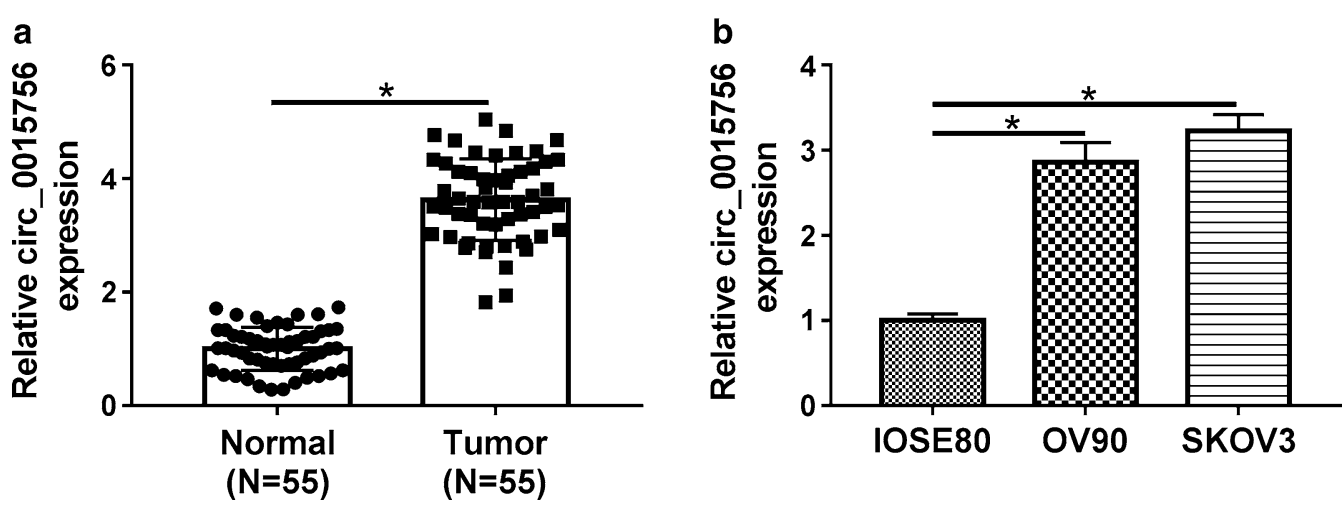

Fig. 1 Circ_0015756 is up-regulated in OC tissues and cells. a The expression of circ_0015756 in OC tissues ( $\mathrm{n}=55)$ and adjacent normal tissues $(n=55)$ was detected using qRT-PCR. b Circ_0015756 level was measured by qRT-PCR in OC cells (OV90 and SKOV3) and normal ovarian epithelial cell line (IOSE80). * $P<0.05$

(See figure on next page.)

Fig. 2 Knockdown of circ_0015756 inhibits the proliferation, migration and invasion of OC cells and induces apoptosis. OV90 and SKOV3 cells were transfected with si-NC or si-circ_0015756, respectively. a The knockdown efficiency of circ_0015756 was determined by qRT-PCR. b, c Cell viability was detected using CCK-8 assay. $\mathbf{d}$ Cell proliferation ability was estimated by colony formation assay. e, $\mathbf{f}$ The levels of proliferation-related proteins (Ki67 and CDK2) were measured by Western blot. $\mathbf{g}$ Flow cytometry was used to detect the proportion of apoptotic cells. h, i Cell migration and invasion capacities were tested by transwell assay (magnification: 100x). j, k The levels of migration and invasion-associated proteins (Snail and MMP9) were examined by Western blot. ${ }^{*} P<0.05$ 

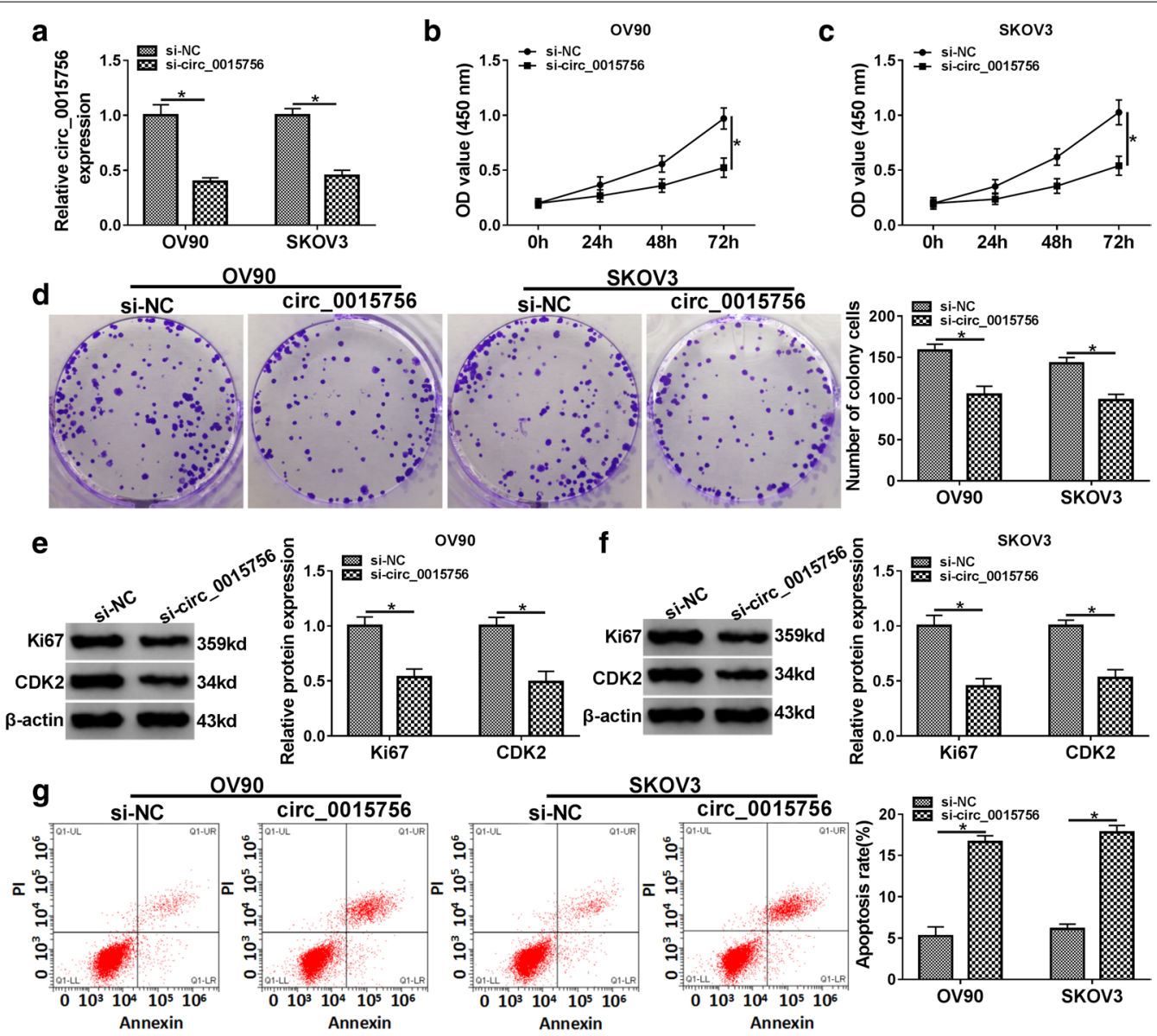

SKov3
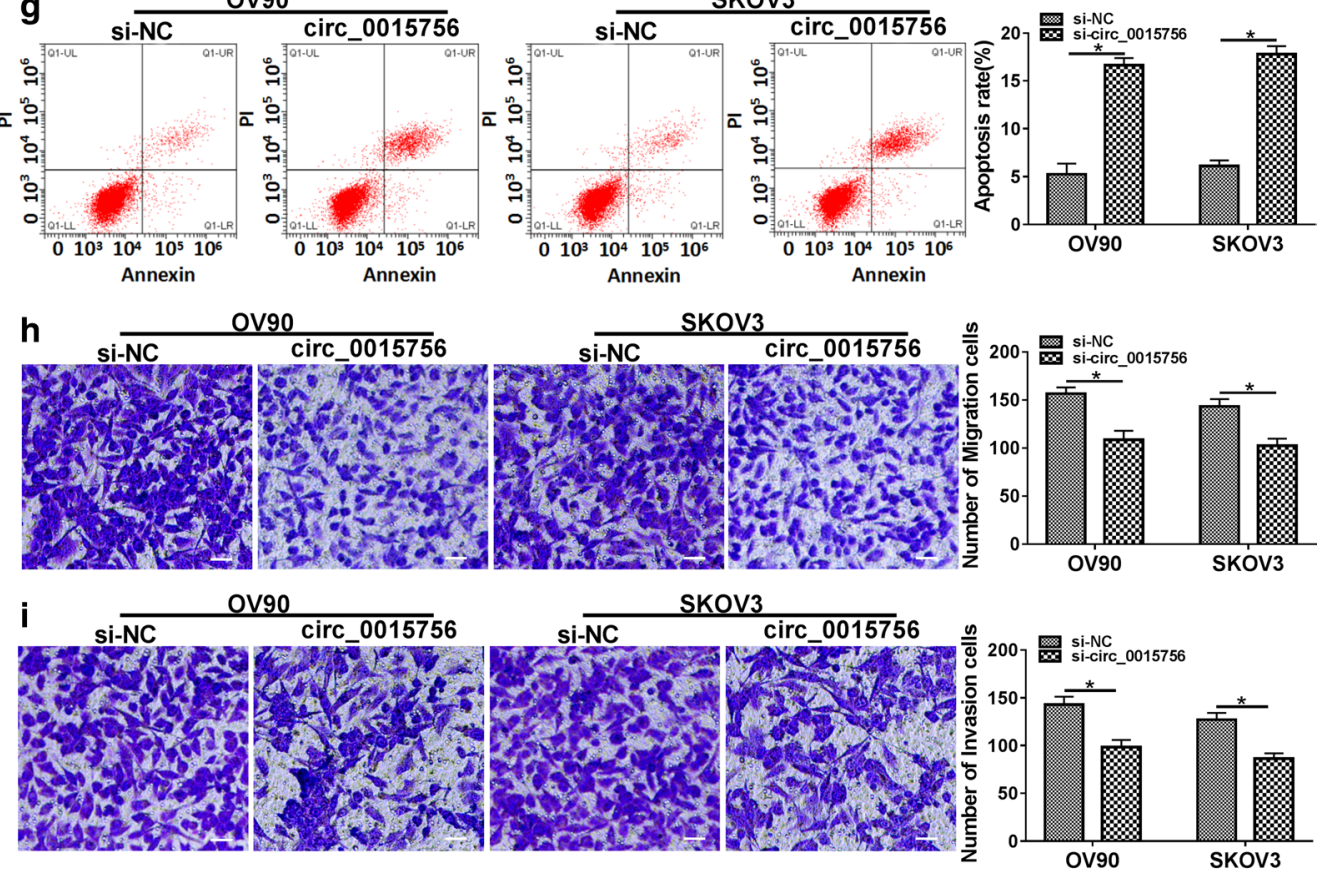

j

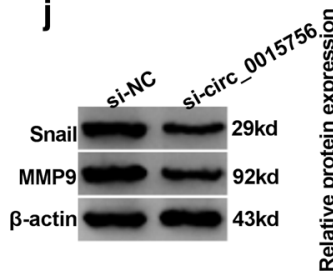

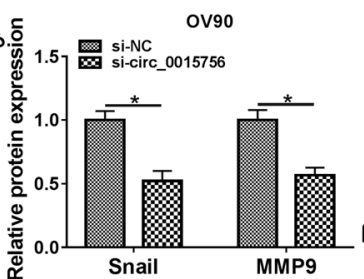

k

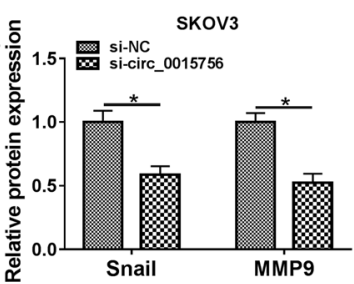




\section{Circ_0015756 acts as a miR-942-5p sponge}

Next, we used three prediction websites (circBank, Starbase 3.0 and circinteractome) to predict potential target miRNAs that might bind to circ_0015756 (Fig. 3a). Subsequently, qRT-PCR was used to detect the expression of four possible targets (miR-942-5p, miR-145-5p, miR-149-5p and miR-224-5p) in OV90 cells transfected with si-NC or si-circ_0015756. The results showed that the up-regulation of miR-942-5p was the most significant after circ_0015756 knockdown, so miR-942-5p was selected as a possible target for circ_0015756 (Fig. 3b). The potential binding site between circ_0015756 and miR-942-5p predicted by the circinteractome database was displayed in Fig. 3c. As illustrated in Fig. 3d, the overexpression efficiency of miR-942-5p was significant. To confirm whether circ_0015756 absorbed miR-942-5p, dual-luciferase reporter assay was performed. The results showed that miR-942-5p mimics significantly decreased the luciferase activity of circ_0015756-WT reporter, but did not affect circ_0015756-MUT reporter (Fig. 3e, f). RIP analysis exhibited that circ_0015756 and miR-942-5p were remarkably enriched in the anti-Ago2 group but not the anti-IgG group (Fig. 3g, h). RNA pull-down assay confirmed that circ_0015756 was pulled down by BiomiR-942-5p instead of Bio-miR-NC (Fig. 3i). In addition, knockdown of circ_0015756 significantly increased the
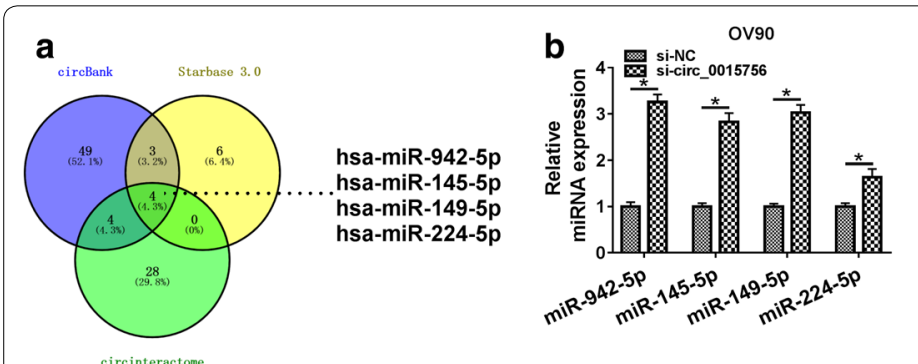

C

hsa_circ_0015756-WT 5'UGCCAUACCCAUGGGAGAGAAGA3'

hsa-miR-942-5p 3'GUGUACCGGUUUUGUCUCUUCU5'

hsa_circ_0015756-MUT 5'UGCCAUACUUGUGGGGUGUCCUA3'

d

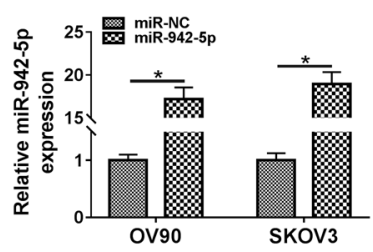

9

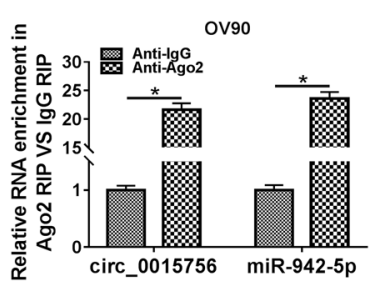

j

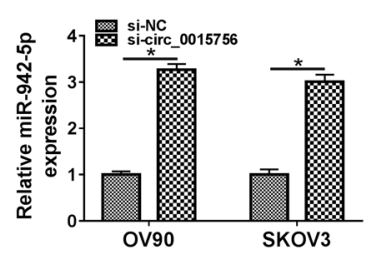

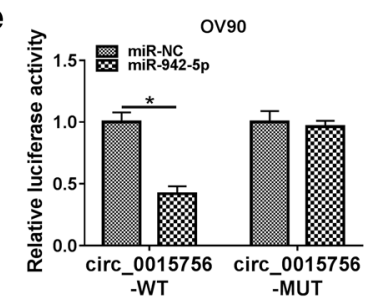

$\mathbf{h}$.

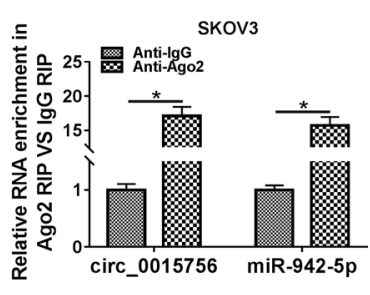

k

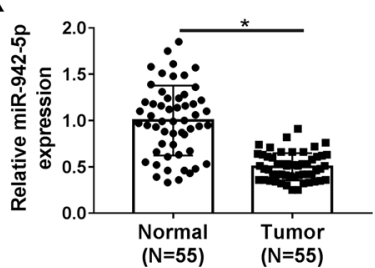

f

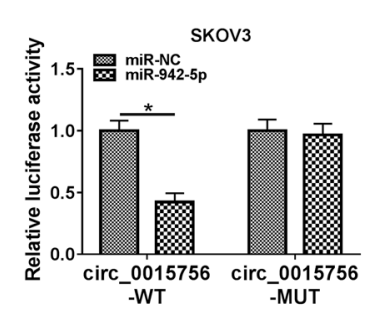

i

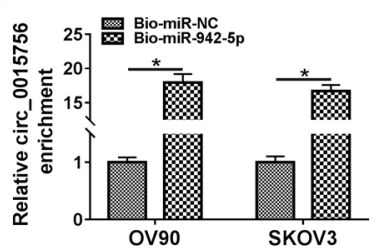

I

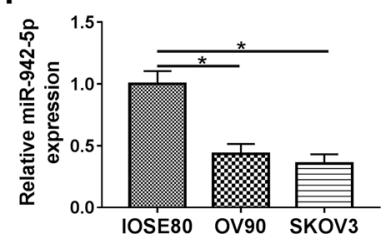

Fig. 3 Circ_0015756 acts as a miR-942-5p sponge. a Three websites (circBank, Starbase 3.0 and circinteractome) were used to predict potential miRNAs that might bind to circ_0015756. b After transfection with si-circ_0015756, the levels of four possible targets (miR-942-5p, miR-145-5p, miR-149-5p and miR-224-5p) were detected. $\mathbf{c}$ The putative binding site between circ_0015756 and miR-942-5p was depicted by circinteractome. d The overexpression efficiency of miR-942-5p was detected by qRT-PCR. The binding relationship between circ_0015756 and miR-942-5p was verified by dual-luciferase reporter assay (e, f), RIP assay $(\mathbf{g}, \mathbf{h})$ and RNA pull-down assay (i) in OV90 and SKOV3 cells. $\mathbf{j}$ The level of miR-942-5p was determined in OV90 and SKOV3 cells transfected with si-NC or si-circ_0015756. $\mathbf{k}$, I The expression of miR-942-5p in OC tissues and cells was tested by $\mathrm{qRT}-\mathrm{PCR} .{ }^{*} P<0.05$ 
expression of miR-942-5p in OC cells (Fig. 3j). Furthermore, miR-942-5p level was markedly reduced in OC tissues and cells compared with the control group (Fig. 3k, 1). Collectively, these data indicated that circ_0015756 negatively regulated miR-942-5p.

\section{Inhibition of miR-942-5p reverses the effect of circ_0015756 knockdown on OC cell progression}

To investigate the role of circ_0015756/miR-942-5p axis in OC cell development, OV90 and SKOV3 cells were transfected with si-circ_0015756 or/and anti-miR942-5p. Firstly, the inhibition efficiency of anti-miR942-5p was determined using qRT-PCR (Fig. 4a). CCK-8, colony formation and Western blot assays revealed that circ_0015756 silencing hindered OC cell proliferation, while this effect was partially abolished by down-regulating miR-942-5p (Fig. 4b-e). Flow cytometry and transwell assays indicated that circ_0015756 knockdown induced cell apoptosis and suppressed cell migration and invasion in OV90 and SKOV3 cells, whereas these impacts were reversed after transfection with anti-miR942-5p (Fig. 4f-h). Moreover, circ_0015756 down-regulation led to a significant decrease in metastasis-related proteins (Snail and MMP9), while this change was partially mitigated by inhibiting miR-942-5p (Fig. 4i). In summary, these data evidenced that circ_0015756 knockdown hindered OC cell progression by regulating miR-942-5p.

\section{CUL4B is a target of miR-942-5p}

To further explore the downstream molecules of miR942-5p, Starbase 3.0 database predicted that miR-942-5p and CUL4B $3^{\prime}$ UTR had a putative binding site (Fig. 5a). Next, dual-luciferase reporter assay and RIP assay were performed to verify the binding relationship between miR-942-5p and CUL4B. The results exhibited that miR942-5p mimics remarkably reduced the luciferase activity of CUL4B 3'UTR-WT reporter, but did not affect CUL4B 3'UTR-MUT reporter (Fig. 5b, c). RIP analysis showed that miR-942-5p and CUL4B were significantly enriched in the anti-Ago2 group compared to the anti-IgG group (Fig. 5d, e). Moreover, up-regulation of miR-942-5p markedly inhibited the expression of CUL4B, while down-regulation of miR-942-5p remarkably promoted the expression of CUL4B (Fig. 5f, g). Compared with the normal tissues, CUL4B mRNA and protein levels were strikingly elevated in $\mathrm{OC}$ tissues (Fig. 5h, i). Also, the mRNA and protein levels of CUL4B in OV90 and SKOV3 cells were markedly higher than that in IOSE80 cells (Fig. 5j, k). These data indicated that miR-942-5p directly targeted CUL4B.

\section{CUL4B reverses the effect of miR-942-5p on OC cell progression}

To elucidate whether miR-942-5p targeted CUL4B to affect OC cell development, OV90 and SKOV3 cells were transfected with miR-942-5p mimics or/and pcDNACUL4B. As displayed in Fig. 6a, b, the overexpression efficiency of CUL4B was confirmed by qRT-PCR and Western blot. Moreover, introduction of miR-942-5p and pcDNA-CUL4B partially abated the inhibitory effect of miR-942-5p mimics on OC cell proliferation (Fig. 6c-g). Furthermore, up-regulation of miR-942-5p remarkably expedited OC cell apoptosis and suppressed the migration and invasion of OV90 and SKOV3 cells, whereas cotransfection of miR-942-5p and pcDNA-CUL4B reversed these effects (Fig. 6h-k). Overall, these results indicated that miR-942-5p inhibited OC cell progression by modulating CUL4B.

\section{Circ_0015756 regulates CUL4B expression by targeting miR-942-5p}

To illuminate the relationship between CUL4B and circ_0015756/miR-942-5p axis, OV90 and SKOV3 cells were transfected with si-NC, si-circ_0015756, sicirc_0015756+anti-miR-NC or si-circ_0015756+antimiR-942-5p. As shown in Fig. 7a, b, co-transfection of si-circ_0015756 and anti-miR-942-5p alleviated the decrease in CUL4B expression caused by circ_0015756 knockdown alone. In addition, Spearman's correlation analysis showed that miR-942-5p was negatively correlated with circ_0015756 or CUL4B, while circ_0015756 was positively correlated with CUL4B in OC tissues (Fig. 7c-e). These data indicated that circ_0015756 sponged miR-942-5p to up-regulate CUL4B expression.

\section{Depletion of circ_0015756 hinders OC growth in vivo}

To investigate the role of circ_0015756 in tumorigenesis in vivo, a xenograft model was established. As shown in Fig. 8a, tumor volume was markedly decreased in the sh-circ_0015756 group compared to the sh-NC group. Down-regulation of circ_0015756

\footnotetext{
(See figure on next page.)

Fig. 4 Inhibition of miR-942-5p reverses the effect of circ_0015756 knockdown on OC cell progression. a The knockdown efficiency of miR-942-5p was measured by qRT-PCR. b-i OV90 and SKOV3 cells were introduced with si-NC, si-circ_0015756, si-circ_0015756+ anti-miR-NC or si-circ_0015756+ anti-miR-942-5p, respectively. b-e Cell proliferation capacity and proliferation-related protein levels were evaluated by CCK-8 assay, colony formation assay and Western blot assay. Cell apoptosis $\mathbf{f}$, migration and invasion $\mathbf{g}$, $\mathbf{h}$ and metastasis-related protein levels $\mathbf{i}$ were detected by flow cytometry, transwell assay and Western blot assay. ${ }^{*} P<0.05$
} 


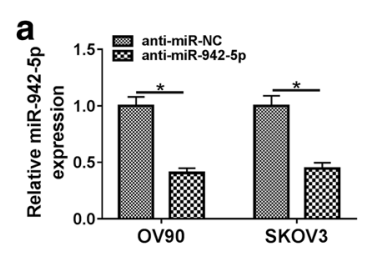

d

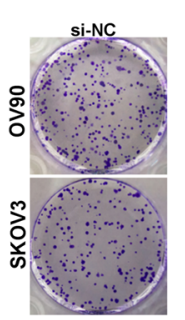

e
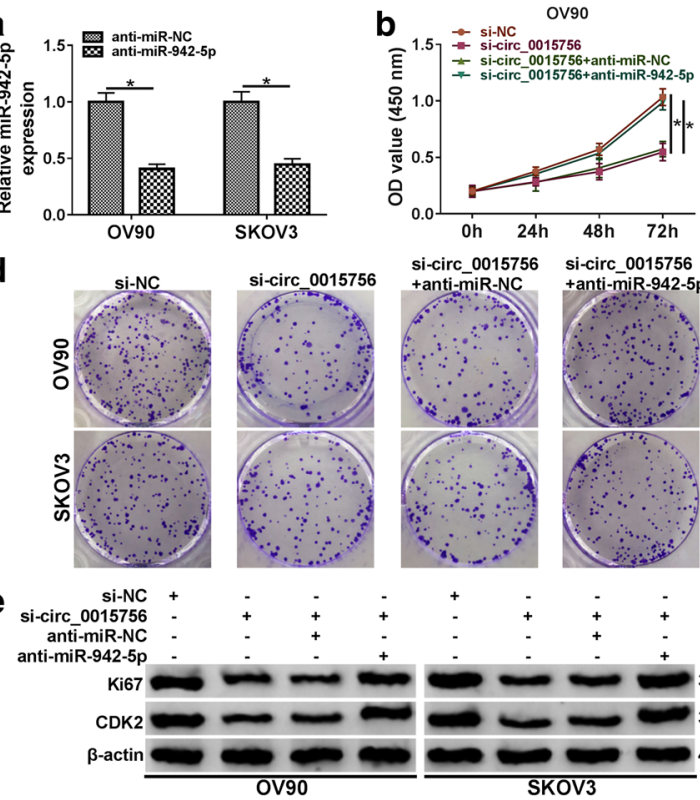

si-circ_0015756
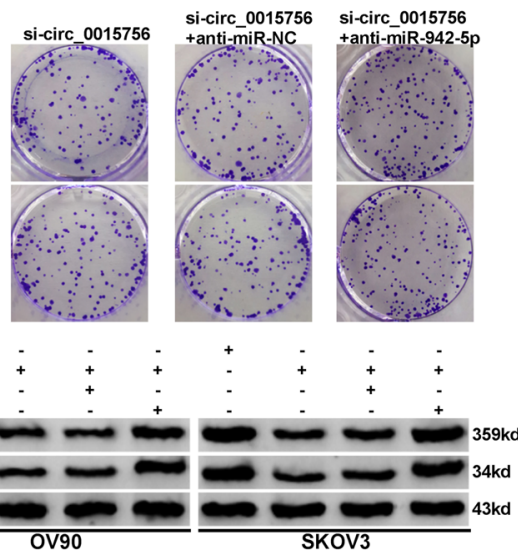

f
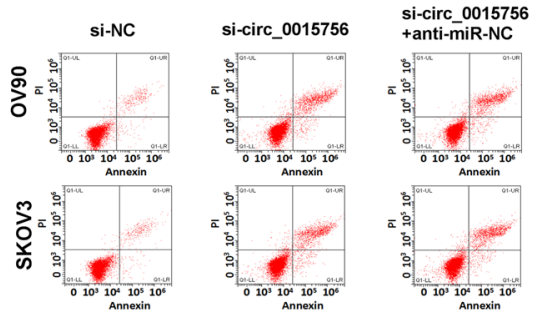

\begin{tabular}{c|c|c|}
\multicolumn{2}{c|}{ si-circ_0015756 } \\
+anti-miR-942-5p \\
\hline
\end{tabular}

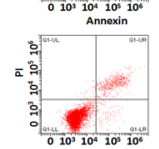

g
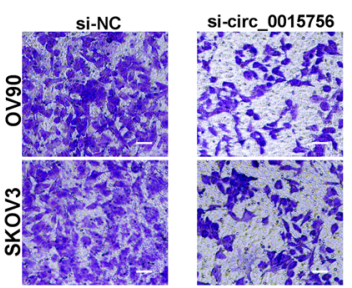

h

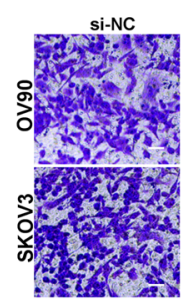

0015756
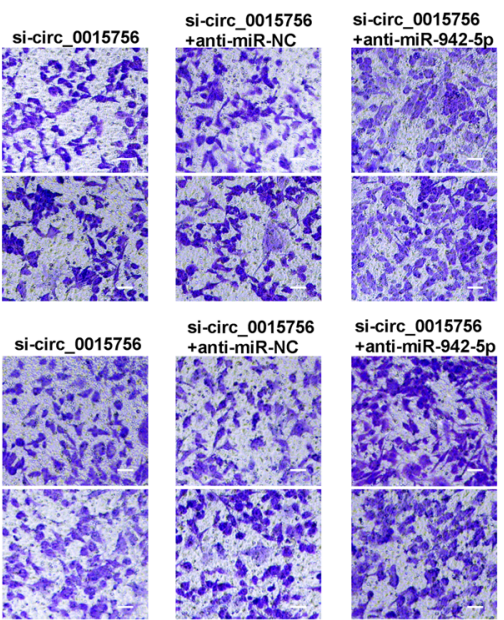

si-circ_0015756

si-circ_0015756
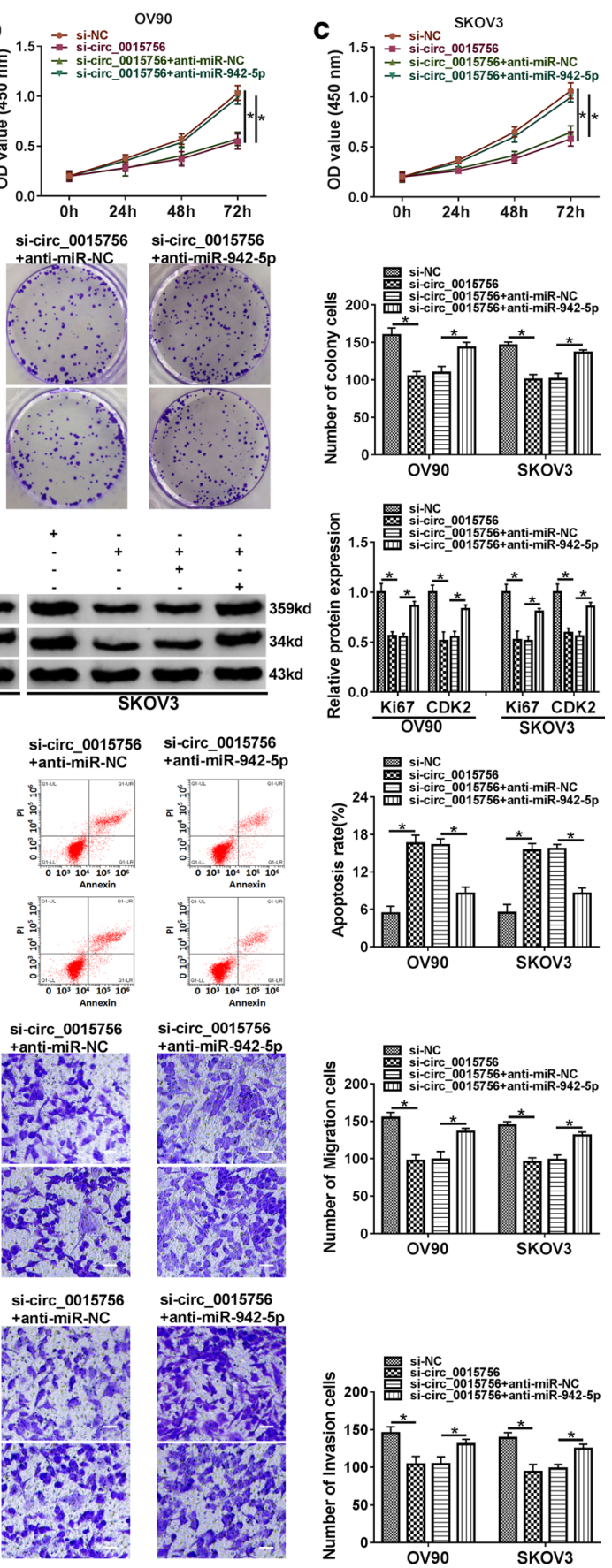

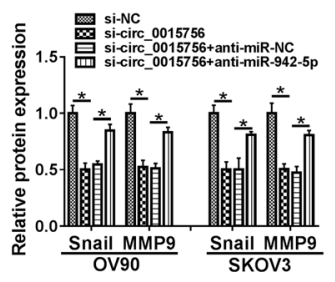




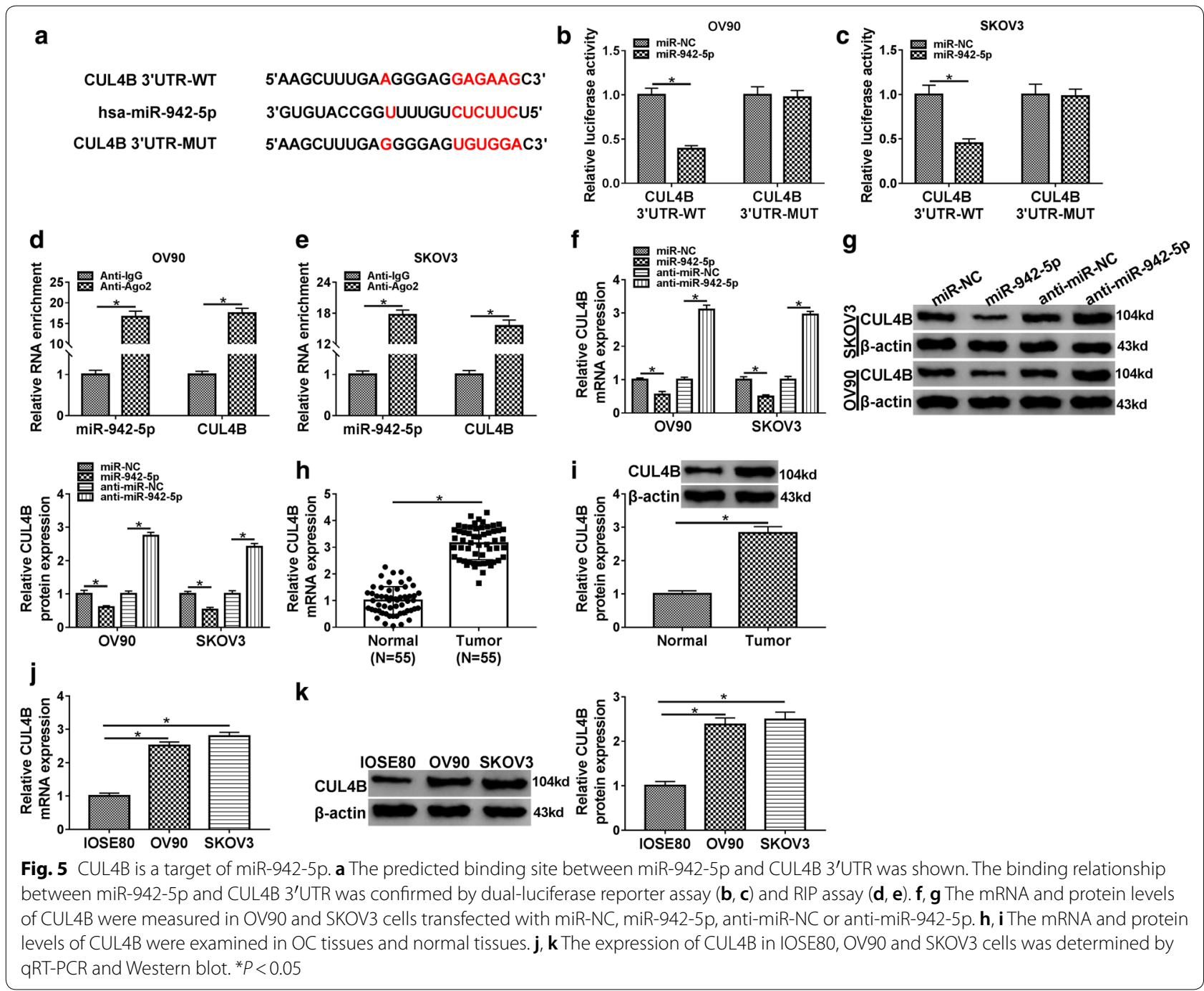

remarkably decreased tumor weight compared with the control group (Fig. 8b). Besides, qRT-PCR and Western blot showed that the expression of circ_0015756 and CUL4B was significantly reduced, and the expression of miR-942-5p was strikingly increased in the shcirc_0015756 group compared to the control group (Fig. 8c-f). These data indicated that circ_0015756 silencing blocked tumor growth in vivo.

\section{Discussion}

Recently, circRNAs have become a hot spot in the field of tumor research. Since most OC patients are diagnosed at the advanced stage, the five-year survival rate is less than 30\% [17]. Hence, exploring new treatment strategies and prognostic indicators is crucial for the clinical efficacy of ovarian cancer. Numerous studies have corroborated that circRNAs are abnormally expressed in OC and have diagnostic and prognostic value in OC $[18,19]$.

(See figure on next page.)

Fig. 6 CUL4B reverses the effect of miR-942-5p on OC cell progression. $\mathbf{a}$, $\mathbf{b}$ The overexpression efficiency of CUL4B was detected by qRT-PCR and Western blot. c-k OV90 and SKOV3 cells were transfected with miR-NC, miR-942-5p, miR-942-5p+pcDNA or miR-942-5p+ pcDNA-CUL4B. CCK-8, colony formation and Western blot assays were utilized to evaluate cell proliferation capacity (c-e) and proliferation-related protein levels (f, $\mathbf{g}$ ). Flow cytometry, transwell and Western blot assays were used to assess cell apoptosis (h), migration and invasion (i, $\mathbf{j})$ and metastasis-related protein levels $(\mathbf{k}) .{ }^{*} P<0.05$ 


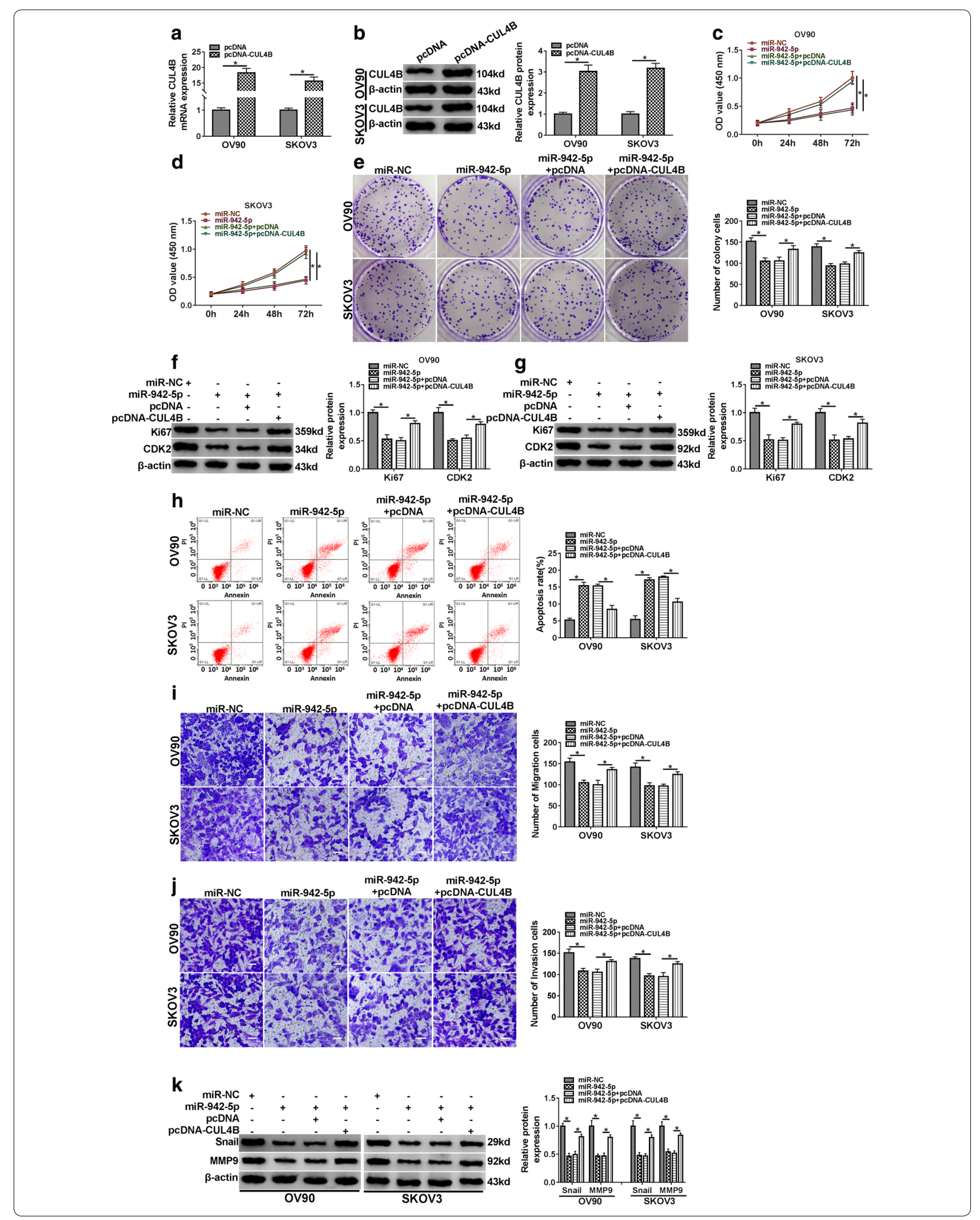



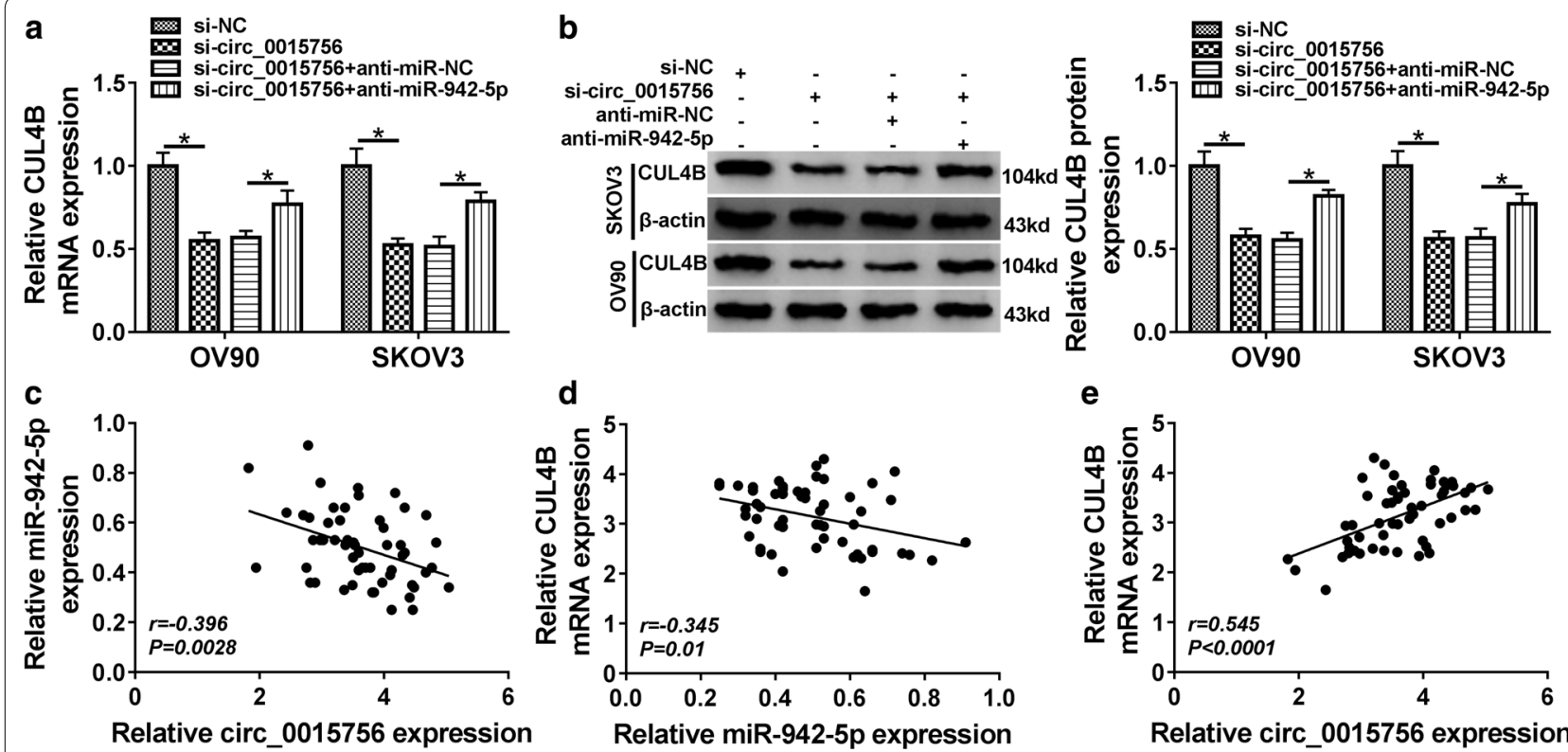

Fig. 7 Circ_0015756 regulates CUL4B expression by targeting miR-942-5p. a, b CUL4B mRNA and protein levels were examined in OV90 and SKOV3 cells transfected with si-NC, si-circ_0015756, si-circ_0015756+ anti-miR-NC or si-circ_0015756+ anti-miR-942-5p. c-e The correlation among circ_0015756, miR-942-5p and CUL4B was detected by Spearman's correlation analysis. ${ }^{*} P<0.05$

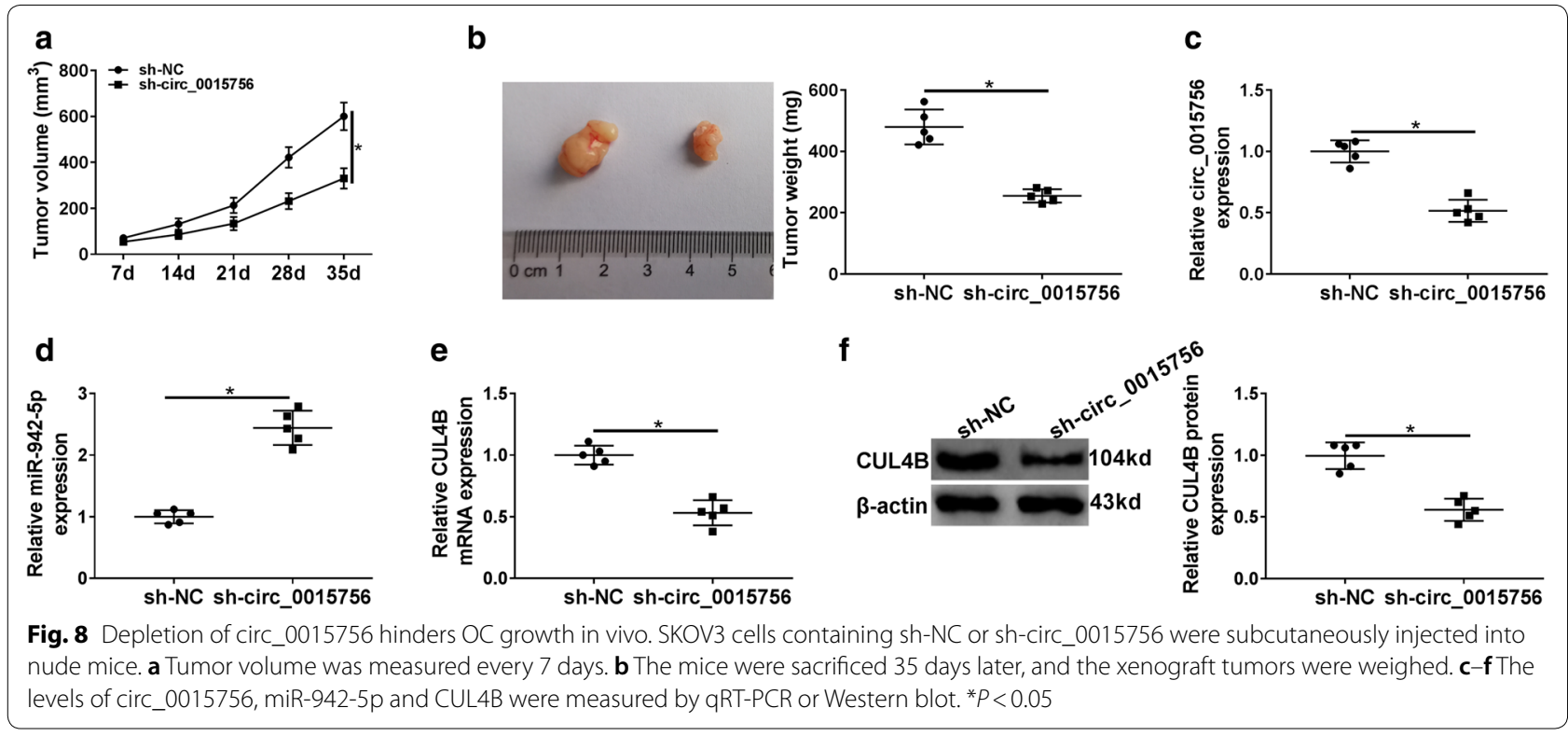

In the present research, circ_0015756 level was strikingly elevated in $\mathrm{OC}$ tissues and cells. Additionally, silencing of circ_0015756 decelerated cell growth and metastasis in OC cells.

Emerging evidence has highlighted that circRNAs competitively bind miRNAs to act as "molecular sponges", thereby attenuating the inhibition of miRNAs on mRNA expression $[20,21]$. In the current research, the potential targets of circ_0015756 were predicted by bioinformatics analysis. According to the expression of four possible target miRNAs after circ_0015756 knockdown, miR-942-5p was selected as the follow-up research object. Several investigations have shown that circRNAs mediate tumor development through serving as a competing endogenous RNA (ceRNA) for miR-942-5p. For example, circRNA-AKT1 contributed to tumor progression in 
cervical cancer via decoying miR-942-5p and up-regulating AKT1 [22]. In addition, circ-CEP85L hindered the malignant phenotype of gastric cancer by absorbing miR-942-5p to increase NFKBIA expression [23]. Herein, we unveiled that circ_0015756 sponged miR-942-5p, and circ_0015756 knockdown suppressed OC progression via modulating miR-942-5p.

In terms of mechanism, we also explored the downstream target genes of miR-942-5p. Increasing evidence has manifested that miRNAs affect mRNA expression via binding to mRNA 3'UTR [24]. Zhang et al. [25] disclosed that miR-942-5p overexpression expedited the malignancy of melanoma through inhibition of DKK3. Luo et al. [26] suggested that up-regulation of miR-942-5p attenuated inflammation and apoptosis of septic AKI by repressing FOXO3. In this research, we discovered that miR-942-5p targeted CUL4B and negatively modulated CUL4B.

CUL4B belongs to the scaffold protein of Cullin4BRing E3 ligase complex [27]. CUL4B is dysregulated in various tumors and participates in many cellular processes related to tumors [28]. CUL4B functions as a carcinogen in diverse tumors, including bladder cancer [29], colorectal cancer [30] and lung adenocarcinoma [31]. In ovarian cancer, CUL4B was overtly up-regulated in cancer tissues and CUL4B facilitated cancer cell proliferation by mediating CDK2 and CyclinD1 [32]. In addition, many proteins regulate mammalian ovarian development by interacting with numerous binding partners. For example, 14-3-3 (YWHA) protein isoforms are expressed in mouse oocytes and eggs and interact with cell cycle division 25B (CDC25B) [33, 34]. 14-3-37, the isoform of YWHA protein, regulates the assembly of microtubules by interacting with $\alpha$-tubulin [35]. In the present research, miR-942-5p targeted CUL4B to suppress OC progression. Furthermore, circ_0015756 elevated CUL4B expression via decoying miR-942-5p.

\section{Conclusion}

In conclusion, circ_0015756 expedited OC progression by sponging miR-942-5p and increasing CUL4B expression. The discovery of circ_0015756/miR-942-5p/CUL4B axis provided a new ceRNA mechanism for OC and a potential therapeutic target for OC treatment. However, the sample size of this study is limited, and a larger sample size is needed to further confirm this conclusion in the future.

\section{Acknowledgements}

Not applicable

\section{Authors' contributions}

Conceptualization and methodology, formal analysis and data curation: LW and YX; validation and investigation: ZD and LW; writing —original draft preparation and writing - review and editing: ZD, LW and YX. All authors read and approved the final manuscript.

\section{Funding}

This work was supported by Natural Science Foundation of Education Department of Liaoning Province (Grant No. JC2019018).

\section{Availability of data and materials}

The analyzed data sets generated during the present study are available from the corresponding author on reasonable request.

\section{Ethics approval and consent to participate}

The present study was approved by the ethical review committee of Shengjing Hospital of China Medical University. Written informed consent was obtained from all enrolled patients.

\section{Consent for publication}

Patients agree to participate in this work.

\section{Competing interests}

The authors declare that they have no competing interests.

Received: 14 September 2020 Accepted: 19 November 2020

Published online: 27 November 2020

\section{References}

1. Jayson GC, Kohn EC, Kitchener HC, Ledermann JA. Ovarian cancer. Lancet. 2014;384(9951):1376-88.

2. Matulonis UA, Sood AK, Fallowfield L, Howitt BE, Sehouli J, Karlan BY. Ovarian cancer. Nat Rev Dis Primers. 2016;2:16061.

3. Tew WP, Muss HB, Kimmick GG, Von Gruenigen VE, Lichtman SM. Breast and ovarian cancer in the older woman. J Clin Oncol. 2014;32(24):2553-61.

4. Longuespee R, Boyon C, Desmons A, Vinatier D, Leblanc E, Farre I, Wisztorski M, Ly K, D'Anjou F, Day R, et al. Ovarian cancer molecular pathology. Cancer Metastasis Rev. 2012;31(3-4):713-32.

5. Qian L, Yu S, Chen Z, Meng Z, Huang S, Wang P. The emerging role of cirCRNAs and their clinical significance in human cancers. Biochim Biophys Acta Rev Cancer. 2018;1870(2):247-60.

6. He J, Xie Q, Xu H, Li J, Li Y. Circular RNAs and cancer. Cancer Lett. 2017;396:138-44.

7. Dong $\mathrm{P}, \mathrm{Xu} \mathrm{D}$, Xiong Y, Yue J, Ihira K, Konno Y, Watari H. The expression, functions and mechanisms of circular RNAs in gynecological cancers. Cancers (Basel). 2020;12(6):1472.

8. Yalan S, Yanfang L, He C, Yujie T. Circular RNA circRHOBTB3 inhibits ovarian cancer progression through PI3K/AKT signaling pathway. Panminerva Med. 2020. https://doi.org/10.23736/s0031-0808.20.03957-9.

9. LiY, Lin S, An N. Hsa_circ_0009910: oncogenic circular RNA targets microRNA-145 in ovarian cancer cells. Cell Cycle. 2020;19(15):1857-68.

10. Wang G, Zhang H, Li P. Upregulation of hsa_circRNA_102958 indicates poor prognosis and promotes ovarian cancer progression through miR1205/SH2D3A axis. Cancer Manag Res. 2020;12:4045-53.

11. Zhang M, Xia B, Xu Y, Zhang Y, Xu J, Lou G. Circular RNA (hsa circ_0051240) promotes cell proliferation, migration and invasion in ovarian cancer through miR-637/KLK4 axis. Artif Cells Nanomed Biotechnol. 2019;47(1):1224-33

12. Chipman $L B$, Pasquinelli AE. miRNA targeting: growing beyond the Seed. Trends Genet. 2019;35(3):215-22.

13. Wang F, Niu G, Chen $X$, Cao F. Molecular imaging of microRNAs. Eur J Nucl Med Mol Imaging. 2011;38(8):1572-9.

14. Yang S, Zhang X, Sun Y, Shi J, Jiang D, Wang J, Liu Y, Hu C, Pan J, Zheng $L$, et al. MicroRNA-362-3p inhibits migration and invasion via targeting BCAP31 in cervical cancer. Front Mol Biosci. 2020;7:107.

15. Zheng X, Xu K, Zhu L, Mao M, Zhang F, Cui L. MiR-486-5p act as a biomarker in endometrial carcinoma: promotes cell proliferation, migration, invasion by targeting MARK1. Onco Targets Ther. 2020;13:4843-53. 
16. Xie J, Wang S, Li G, Zhao X, Jiang F, Liu J, Tan W. circEPSTI1 regulates ovarian cancer progression via decoying miR-942. J Cell Mol Med. 2019;23(5):3597-602.

17. Trinidad CV, Tetlow AL, Bantis LE, Godwin AK. Reducing ovarian cancer mortality through early detection: approaches using circulating biomarkers. Cancer Prev Res (Phila). 2020;13(3):241-52.

18. Yang X, Mei J, Wang H, Gu D, Ding J, Liu C. The emerging roles of circular RNAs in ovarian cancer. Cancer Cell Int. 2020;20:265.

19. Feng Y, Wang Q, Shi C, Liu C, Zhang Z. Does circular RNA exert significant effects in ovarian cancer? Crit Rev Eukaryot Gene Expr. 2019;29(2):161-70.

20. Tang Q, Hann SS. Biological roles and mechanisms of circular RNA in human cancers. Onco Targets Ther. 2020;13:2067-92.

21. Dori M, Bicciato S. Integration of bioinformatic predictions and experimental data to identify circRNA-miRNA associations. Genes (Basel). 2019;10(9):642.

22. Ou R, Mo L, Tang H, Leng S, Zhu H, Zhao L, Ren Y, Xu Y. circRNA-AKT1 sequesters miR-942-5p to upregulate AKT1 and promote cervical cancer progression. Mol Ther Nucleic Acids. 2020;20:308-22.

23. Lu J, Wang YH, Huang XY, Xie JW, Wang JB, Lin JX, Chen QY, Cao LL, Huang CM, Zheng $\mathrm{CH}$, et al. circ-CEP85L suppresses the proliferation and invasion of gastric cancer by regulating NFKBIA expression via miR-942-5p. J Cell Physiol. 2020;235(9):6287-99.

24. Zhang S, Lu Z, Unruh AK, Ivan C, Baggerly KA, Calin GA, Li Z, Bast RC Jr, Le XF. Clinically relevant microRNAs in ovarian cancer. Mol Cancer Res. 2015;13(3):393-401.

25. Zhang W, Mao K, Liu S, Xu Y, Ren J. miR-942-5p promotes the proliferation and invasion of human melanoma cells by targeting DKK3. J Recept Signal Transduct Res. 2020. https://doi.org/10.1080/10799893.2020.18042 80.

26. Luo N, Gao HM, Wang YQ, Li HJ, Li Y. MiR-942-5p alleviates septic acute kidney injury by targeting FOXO3. Eur Rev Med Pharmacol Sci. 2020;24(11):6237-44.
27. Hannah J, Zhou P. Distinct and overlapping functions of the cullin E3 ligase scaffolding proteins CUL4A and CUL4B. Gene. 2015;573(1):33-45.

28. Li Y, Wang $X$. The role of cullin $4 B$ in human cancers. Exp Hematol Oncol. 2017;6:17.

29. Liu X, Cui J, Gong L, Tian F, Shen Y, Chen L, Wang Y, Xia Y, Liu L, Ye X, et al. The CUL4B-miR-372/373-PIK3CA-AKT axis regulates metastasis in bladder cancer. Oncogene. 2020;39(17):3588-603.

30. Li Y, Hu H, Wang Y, Fan Y, Yang Y, Guo B, Xie X, Lian J, Jiang B, Han B, et al. CUL4B contributes to cancer stemness by repressing tumor suppressor miR34a in colorectal cancer. Oncogenesis. 2020;9(2):20.

31. Zhang H, Wang A, Tan Y, Wang S, Ma Q, Chen X, He Z. NCBP1 promotes the development of lung adenocarcinoma through up-regulation of CUL4B. J Cell Mol Med. 2019;23(10):6965-77.

32. Duan PJ, Zhao JH, Xie LL. Cul4B promotes the progression of ovarian cancer by upregulating the expression of CDK2 and CyclinD1. J Ovarian Res. 2020;13(1):76.

33. Eisa AA, De S, Detwiler A, Gilker E, Ignatious AC, Vijayaraghavan S, Kline D. YWHA (14-3-3) protein isoforms and their interactions with CDC25B phosphatase in mouse oogenesis and oocyte maturation. BMC Dev Biol. 2019;19(1):20

34. De S, Marcinkiewicz JL, Vijayaraghavan S, Kline D. Expression of 14-3-3 protein isoforms in mouse oocytes, eggs and ovarian follicular development. BMC Res Notes. 2012;5:57.

35. De S, Kline D. Evidence for the requirement of 14-3-3eta (YWHAH) in meiotic spindle assembly during mouse oocyte maturation. BMC Dev Biol. 2013;13:10.

\section{Publisher's Note}

Springer Nature remains neutral with regard to jurisdictional claims in published maps and institutional affiliations.
Ready to submit your research? Choose BMC and benefit from:

- fast, convenient online submission

- thorough peer review by experienced researchers in your field

- rapid publication on acceptance

- support for research data, including large and complex data types

- gold Open Access which fosters wider collaboration and increased citations

- maximum visibility for your research: over $100 \mathrm{M}$ website views per year

At $\mathrm{BMC}$, research is always in progress.

Learn more biomedcentral.com/submissions 